\title{
Satisfaction Levels of Elderly People regarding the Existing Lighting Levels while Performing ADL and IADL Activities
}

\author{
Varnam Radhika $^{1 *}$, D. Ratna Kumari ${ }^{1}$, Swetha Kodali ${ }^{1}$ and S. L. Kameswari ${ }^{2}$ \\ ${ }^{1}$ Department of Family Resource Management, ${ }^{2}$ Department of Extension Education and \\ Communication Management, Hyderabad, Professor JayashankarTelangana State \\ Agricultural University, Telangana, India \\ *Corresponding author
}

\section{Keywords}

Satisfaction levels, ADL (Activities of Daily Living), IADL (Instrumental Activities of Daily Living)

Article Info

Accepted:

26 July 2020

Available Online:

10 August 2020

\section{A B S T R A C T}

The present study was assumed to detect the satisfaction levels of lighting while performing ADL (Activities of Daily Living) / IADL (Instrumental Activities of Daily Living) activities. Exploratory research design was used and a sample of 50 elderly people was selected through purposive random sampling method and collected data through a structured interview cum observation schedule. The results revealed that Majority $(33.7 \%)$ of the respondents were averagely satisfied with existing lighting while performing ADL activities which belongs to 56-60 years of age group. Least (one per cent) of the respondents were extremely dissatisfied which belonged to 76-80 years of age group. Majority (35\%) of the male respondents were satisfied with existing lighting while performing ADL activities. Least $(1.5 \%)$ of the respondents were extremely dis satisfied with existing lighting for ADL activities.

\section{Introduction}

Lighting is an art element plays a major role in aesthetics of a building design. But it is also important because it affects human beings both psychologically and physiologically (Manav and Yener, 1999). Sabia (2008), in their studies mentioned that there is empirical evidence that older people find it more difficult to move in their households because of poor lighting. Elderly has been defined as a chronological age of 65 years old or older, while those from 65 through 74 years old are referred to as "early elderly" and those over 75 years old as "late elderly" (Orimo et al., 2006).

The main objectives of the study include to study the satisfaction levels of lighting with regards to age and gender. 


\section{Materials and Methods}

Exploratory research design was followed in the present study. Most of the apartments were located in Hyderabad and Secunderabad cities of Telangana state.

Sample size was 50 respondents from that 25 female and 25 male respondent's age between 55 to 80 years living in apartments. Purposive sampling technique was selected as the study designed specially for elderly/aged that belongs to 56-80 years of age.

The collected data was systematized, tabulated and classified using qualitative and quantitative classification and subjected to statistical tests. The statistical tools were Frequency, Percentage and Mean percent score.

\section{List of ADL and IADL activities used to collect data under this study}

ADLs: Activities of Daily Living

Eating

Bathing

Dressing

Toileting (Katz et al., 1970)

IADLs: Instrumental Activities of Daily Living

Food preparation

Reading

Managing medications

Shopping (Lawton and Brody, 1969;

Talarska et al., 2015).

\section{Results and Discussion}

The satisfaction levels of lighting among the respondents while performing ADL and IADL activities with regards to their age and gender were discussed below. The scores obtained were ES- Extremely satisfied, SSatisfied, A- Average, DS- Dissatisfied and EDS- Extremely dissatisfied which weighs for $5,4,3,2$ and 1 respectively.

\section{Satisfaction levels of lighting with regards to age}

Figure 1 reveals the results related to scores obtained by the respondents while performing the activities under the existing indoor lighting with regards to age. The scores obtained were ES- Extremely satisfied, SSatisfied, A- Average, DS- Dissatisfied and EDS- Extremely dissatisfied which weighs for $5,4,3,2$ and 1 respectively.

Average scores of ADL activities achieved were 8.75 for extremely satisfied 31 for satisfied, 33.75 for average and 5.5 for dissatisfied in the age group of 56-60. Age group of 61-65 scored 22.5, 8, 15 and 2 for extremely satisfied, satisfied, average and dissatisfied respectively. Scores in the age group of 66-70 were 5,10,9 and 2 for extremely satisfied, satisfied, average and dissatisfied respectively. The age groups of 71-75 scores were satisfied (13), average (7.5) dissatisfied (2) and extremely dissatisfied (1). Scores of 76-80 years of age group were extremely satisfied (5), satisfied (6), average (4) and dissatisfied (2).

Average scores of IADL activities achieved were extremely satisfied (5), satisfied (13), average (19.5) and dissatisfied (8.5)belonged to the age group of 55-60. Scores achieved in the age group of 61-65 were extremely satisfied (10), satisfied (4), average (12) and dissatisfied (3.33). In the age group of 66-70 scores were satisfied (7), average (6) and dissatisfied (2.66). In the age group of 71-75 scores obtained were satisfied (8), average (4.5) and dissatisfied (6).Scores of 76-80 years of age group was only average (6). 
From the Figure 1 it was clear that most of the respondents were extremely satisfied, satisfied and averagely satisfied in all age groups.

Very few respondents were extremely dissatisfied amid the age group of 56-60 years. Generally as age increases satisfaction level of respondents upon the existing indoor lighting decreases due to reduction of eye sight this might be because the sample of the present study mostly belongs to $56-60$ years of age group.
Satisfaction levels of lighting with regards to gender

Figure 2 reveals the satisfaction levels of the respondents while performing ADL activities among male were satisfied (35\%), averagely satisfied (about 30\%), extremely satisfied (about 22\%), however only three and about two per cent men were dissatisfied and extremely dissatisfied respectively. Similarly, female respondent's scores were extremely satisfied (15\%), satisfied (26\%), averagely satisfied (34\%), dissatisfied (eight per cent) and extremely dissatisfied $(11 \%)$.

Figure.1 Age Distribution of for the Satisfaction level scores while performing ADL and IADL activities under existing indoor lighting

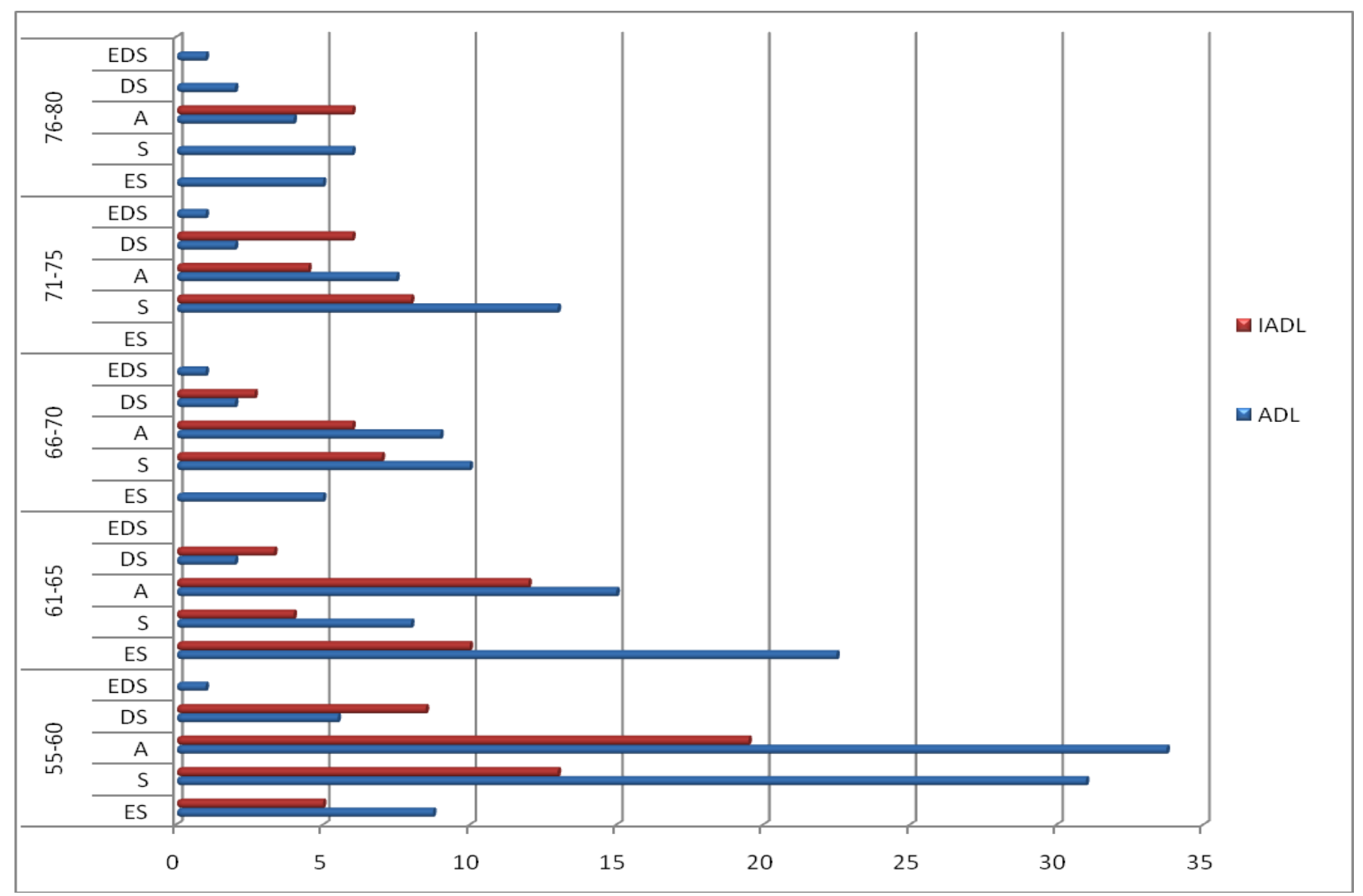

* ES - Extremely satisfied * S - Satisfied * A - Averagely satisfied * DS - Dissatisfied * EDS - Extremely dissatisfied 
Figure.2 Gender Distribution for the Satisfaction levels scores while performing ADL and IADL activities under existing indoor lighting

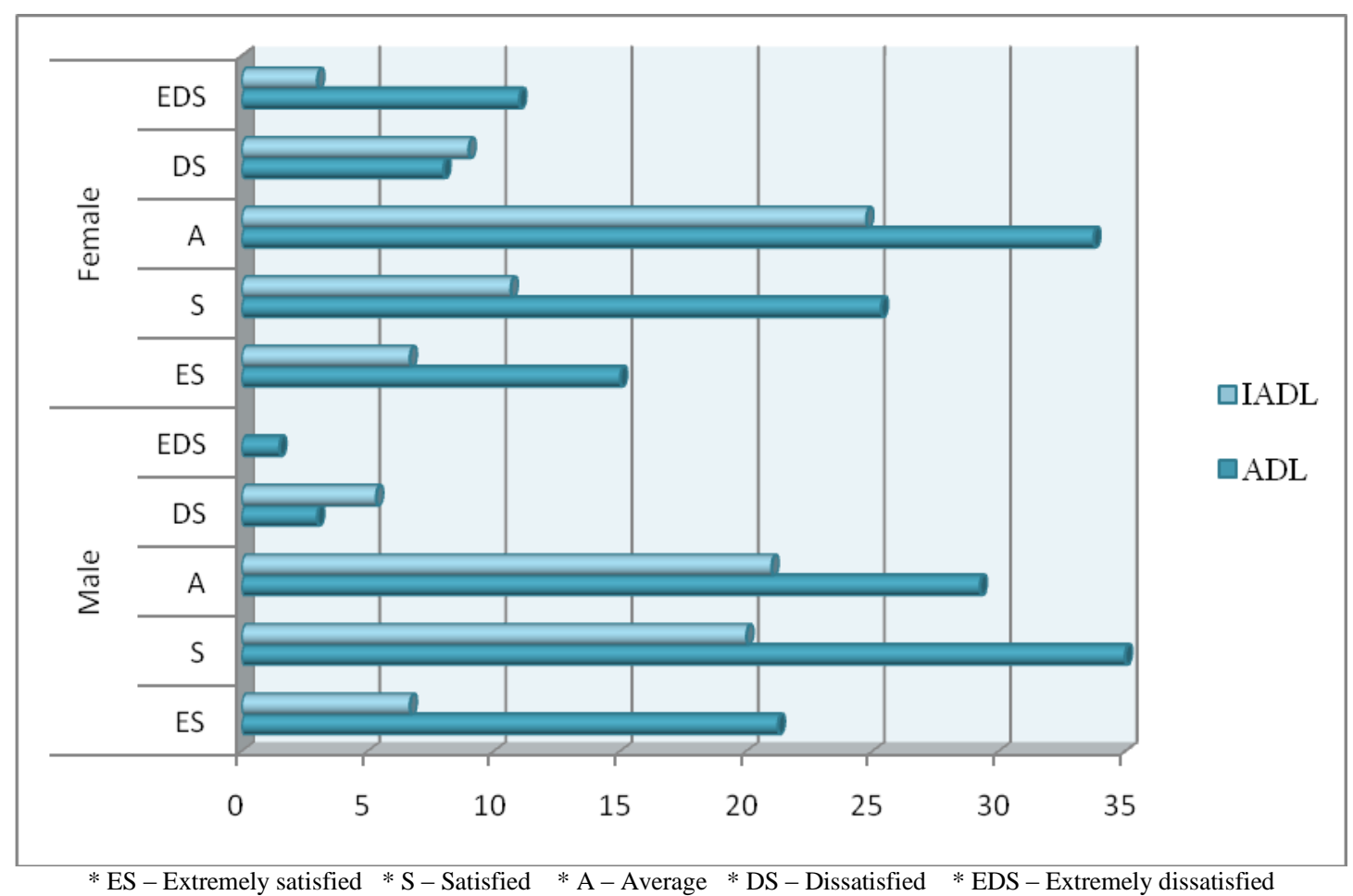

Satisfaction levels for the IADL activities among male were averagely satisfied (21\%), satisfied (20\%), extremely satisfied (about seven per cent), and dissatisfied (about six per cent). Female respondent's scores were extremely satisfied (about seven per cent), satisfied (about 11\%)), averagely satisfied (about 25\%), dissatisfied (nine per cent) and extremely dissatisfied (three per cent).

From the figure 2 it can be concluded that, compared to the male respondents' female respondents were extremely dissatisfied especially while performing bathing and food preparation activities under existing indoor lighting. Compared to female respondents' male respondents were extremely satisfied except food preparation activity as it was mainly done by females. Most of the respondents were satisfied while performing ADL activities compare to IADL activities because IADLs require more lighting to perform than ADLs. The reason for the dissatisfaction as reported by Duijnhoven, et. $a l$. , (2017), that the absence of uncomfortably bright or dim lighting, a poor lighting distribution, reflections from light fixtures, and too bright light fixtures led to a poor satisfaction with lighting.

The present study concluded that compared to the male respondents' female respondents were extremely dissatisfied especially while performing bathing and food preparation activities under existing indoor lighting. Compared to female respondents' male respondents were extremely satisfied except food preparation activity as it was mainly done by females.

Most of the respondents were extremely satisfied, satisfied and average in all age groups very few respondents were extremely dissatisfied and in the age group of 56-60 years. 
While performing ADL activities, IADL activities require more lighting so respondents were more satisfied while performing ADLs than IADLs.

\section{References}

Duijnhoven, J.V., Aarts, M., Rosemann, A.L.P. and Kort, H.S.M. 2017.Office lighting characteristics determining occupant's satisfaction and health. Conference Paper.

Katz, S., Down, T. D., Cash, H. R and Grotz, R. C. 1970. Progress in the development of the index of ADL. The Gerontologist. 10(1): 20-30. https://doi.org/10.1093/geront/10.1_Part - 1.20

Lawton, M. P and Brody, E. M. 1969. Assessment of older people: Selfmaintaining and instrumental activities of daily living. The Gerontologist. 9(3): 179-186.
Manav, B and Yener, C. 1999. Effects of different lighting arrangements on space perception: Architectural Science. 42(1): 43-47.

Orimo, H., Ito, H., Suzuki, T., Araki, A., Hosoi, T and Sawabe, M. 2006. Reviewing the Definition of Elderly. Geriatrics and Gerontology International. $6: 149-158 . \quad$ DOI: 10.1111/j.1447-0594.2006.00341.

Sabia, J. J. 2008. There's no place like home: A hazard model of aging in place among older homeowners in the PSID. Research on Aging.30: 3-35.

Talarska, D., Pacholska, R., Strugała, M and Wieczorowska-Tobis, K. 2015. Functional assessment of the elderly with the use of easy-Care Standard 2010 and Comprehensive Geriatric Assessment. Scandinavian Journal of Caring $\quad$ Sciences. doi:10.1111/scs.12241.

\section{How to cite this article:}

Varnam Radhika, D. Ratna Kumari, Swetha Kodali and Kameswari, S. L. 2020. Satisfaction Levels of Elderly People Regarding the Existing Lighting Levels while Performing ADL and IADL Activities. Int.J.Curr.Microbiol.App.Sci. 9(08): 3311-3315. doi: https://doi.org/10.20546/ijcmas.2020.908.379 